\title{
Blood Platelets and Myocardial Infarction: Do Hyperactive Platelets Really Exist?*
}

\author{
Rüdiger E. Scharf Rainer B. Zotz \\ Institut für Hämostaseologie und Transfusionsmedizin, Universitätsklinikum Düsseldorf, Heinrich-Heine-Universität, Düsseldorf, Germany
}

\section{Key Words}

Myocardial infarction - Platelet receptor

polymorphisms · Platelet thrombogenicity · Human

platelet antigens (HPA) - Arterial thrombogenesis

\section{Summary}

The existence of platelet 'hyperreactivity' as a trigger of acute vascular events has been postulated clinically for decades. However, the molecular nature of an intrinsically enhanced platelet function remained unknown. Recently, a possible explanation was provided in that several genetically determined variants of platelet glycoprotein receptors can be responsible for an increased thrombogenicity and thereby accelerate acute occlusive complications of arterial disease. Distinct polymorphisms within the genes of platelet membrane glycoprotein receptors can alter their antigenicity, regulate, at least in part, their expression levels on the platelet surface, and modify their functional properties with regard to ligand binding and adhesion activity. This review will focus on 2 essential platelet receptors, the integrins $\alpha \operatorname{llb} \beta 3$ and $\alpha 2 \beta 1$, their polymorphisms, and their potential clinical impact of genetically determined receptor variants on cardiovascular disease. Moreover, the genotype-to-phenotype relation of relevant platelet receptor variants will be discussed, and an attempt is made to assess the interdependency of phenotype to disease.
*Dedicated to Prof. Dr. Peter Hanfland, Bonn, on the occasion of his 65th birthday.

\author{
Schlüsselwörter \\ Myokardinfarkt · Plättchen-Rezeptor-Polymorphismen . \\ Plättchenthrombogenität · Humane Plättchenantigene \\ (HPA) · Arterielle Thrombogenese
}

\section{Zusammenfassung}

Seit Jahrzehnten wird klinisch die Existenz hyperaktiver Plättchen postuliert. Allerdings ist die molekulare Natur einer gesteigerten Plättchenfunktion bislang unbekannt geblieben. Kürzlich wurde nun eine mögliche Erklärung geliefert, dass bestimmte genetisch determinierte Varianten thrombozytärer Glykoproteinrezeptoren eine erhöhte Thrombogenität hervorrufen und dadurch akute okklusive Komplikationen arterieller Gefäßerkrankungen auslösen können. Bestimmte Polymorphismen in den Genen thrombozytärer Membranrezeptoren können deren Antigenität ändern, die Expression der Rezeptoren auf der Plättchenoberfläche zumindest teilweise steuern und funktionelle Eigenschaften wie Ligandenbindung und Adhäsionsaktivität modulieren. Diese Übersicht befasst sich mit 2 essentiellen Plättchenrezeptoren, den Integrinen $\alpha$ llb $\beta 3$ und $\alpha 2 \beta 1$, deren Polymorphismen und der potentiellen Auswirkung genetisch determinierter Rezeptorvarianten auf kardiovaskuläre Erkrankungen. Darüber hinaus soll die Genotyp-Phänotyp-Korrelation relevanter Rezeptorvarianten diskutiert und eine vorläufige Beurteilung der Wechselbeziehung von Phänotyp und Krankheit vorgenommen werden. 


\section{Introduction}

Blood platelets play a pivotal role in hemostasis and arterial thrombogenesis. They are anuclear fragments derived from the cytoplasma of megakaryocytes. Upon release from the bone marrow into the circulation, platelets contribute essentially to survey the integrity of the vascular system. Specifically, they respond immediately to vascular lesions by becoming adherent within milliseconds and by forming aggregates at sites of injured endothelial cells or exposed subendothelial matrix structures. Following activation, platelets provide a highly effective catalytic membrane surface for the generation of thrombin which, in turn, accelerates recruitment of circulating resting platelets and, particulary, formation of fibrin necessary to stabilize thrombi and to prevent their detachment by flowing blood. Once stimulated, platelets respond uniformly and do not distinguish between traumatic injury and pathological (e.g. atherosclerotic) damage of the vessel wall. While their physiological function is to support arrest of bleeding, to contribute to wound healing and to restore vessel wall integrity, platelets can form occlusive thrombi as a consequence of vascular diseases, such as atherosclerosis. Thus, under pathological conditions, platelet responses can result in acute ischemic syndromes of the heart, brain and other organ systems. This review will address the nature of increased platelet thrombogenicity with emphasis on the role of distinct platelet membrane receptor polymorphisms. Moreover, the genotype-to-phenotype and the phenotype-to-disease relations of specific platelet integrin variants will be discussed in further detail.

\section{The Prethrombotic State and Platelet Hyperaggregability}

Numerous experimental and clinical studies have documented that acute vascular events cause platelet activation and formation of platelet thrombi which, in turn, can lead to unstable angina, myocardial infarction or stroke [1-3]. For example, platelet activation occurs at the site of a fissured coronary atherosclerotic plaque with exposure of highly thrombogenic substances. We have examined the effect of angioplasty-injured coronary arteries on platelet activation [4]. Using flow cytometric techniques in combination with specific conformationdependent monoclonal antibodies (mAbs), activated platelets could be demonstrated in patients undergoing percutaneous transluminal coronary angioplasty (PTCA) (fig. 1). By contrast to these conditions in which platelet activation and thrombus formation emerge in response to the exposure of subendothelial extracellular matrix proteins, less well documented and perhaps less frequently, are several clinical settings in which an acute vascular event appears to result from an intrinsic platelet activation.

We studied 47 patients (12 males, 35 females, $<45$ years of age) with cerebral ischemia (stroke) of unknown cause and 36 patients (6 males, 30 females, mean age 38 years) suffering from migraine accompagnée [2]. Elevated plasma concentrations of platelet-specific proteins, including $\beta$-thromboglobulin ( $\beta \mathrm{TG})$ and platelet factor 4 (PF4), were found in 33 of the 47 patients with stroke $(70 \%)$ and in 25 of the 36 patients with migraine accompagnée (69\%). Interestingly, the plasma levels of $\beta$ TG and PF4 correlated inversely $(r=-0.72, p<0.001)$ with the interval between time of the migraine attack and blood collection (fig. 2), suggesting a direct association of increased platelet secretion with clinical symptoms [2]. This observation is in accordance with findings from others who reported on an augmented rate of circulating platelet aggregates in patients with migraine accompagnée, in particular at the time of a migraine attack [5].

Along with suchlike findings, it has been postulated clinically that hyperactive or hyperreactive platelets exist in affected individuals $[6,7]$. From a laboratory point of view, this condition has been termed platelet hyperaggregability, defined as a feature in which the threshold concentration for aggregating agents, including adenosine diphosphate (ADP), epinephrine and collagen, is lowered in patients $[6,8]$ and, as very recently demonstrated, also in healthy individuals [7]. This phenomenon has to be carefully distinguished from the so-called 'sticky platelet syndrome', an autosomal dominant platelet disorder characterized by hyperaggregability of platelets in response to ADP and epinephrine (type I), epinephrine alone (type II) or ADP alone (type III) and associated with arterial and/or venous thrombembolic events [9]. In a more general way, the term 'prethrombotic state' has been introduced. This state is postulated to represent a condition which precedes clinically overt thrombosis, during which the hemostatic function is altered in a way that promotes formation or deposition of platelet thrombi and generation of fibrin [6]. This definition raises several questions: i) What are the markers of such a prethrombotic state and ii) what is its molecular nature? In this context, polymorphisms of platelet membrane glycoproteins have come into the focus of interest.

\section{Polymorphisms of Platelet Membrane Glycoproteins}

Polymorphisms are stable DNA sequence variations that occur in more than $1 \%$ of chromosomes in the general population. Platelet membrane glycoproteins are highly polymorphic and can be recognized as self-antigens or alloantigens. Incompatibility of distinct epitopes, also known as human platelet antigens, on the various platelet membrane receptors is responsible for alloimmune thrombocytopenias and some cases of platelet transfusion refractoriness. Moreover, 'mismatches' play an important role in the pathogenesis of fetal or neonatal alloimmune thrombocytopenia and posttransfusion purpura. Among platelet membrane glycoproteins, a variety of adhesion receptors of the integrin and nonintegrin family has been identified. Most receptors carry distinct polymorphisms which are summarized in table 1. 
a
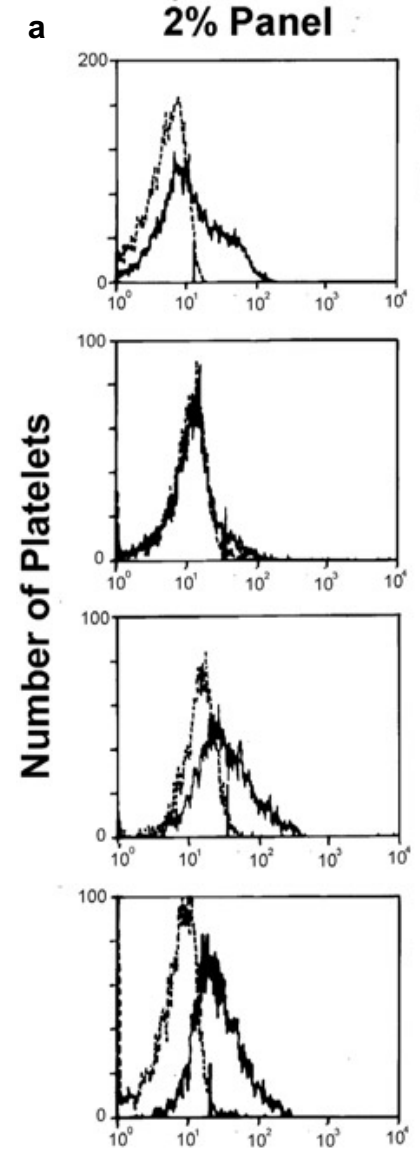

$10 \%$ Panel

PAC

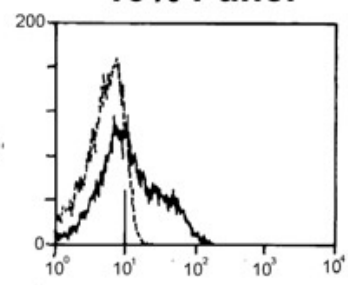

9F9

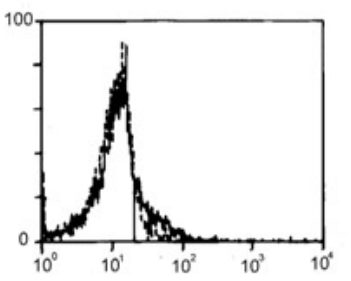

anti-

LIBS1

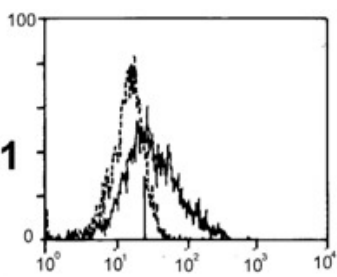

S12

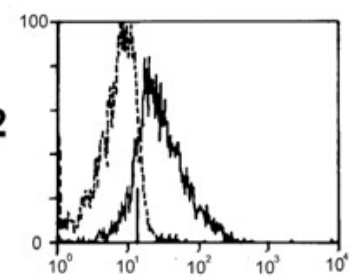

b
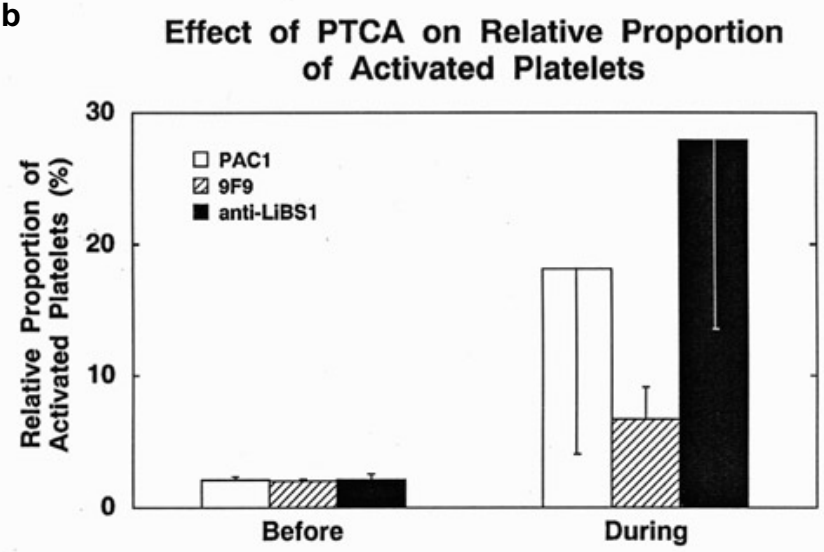

Membrane Immunofluorescence

Fig. 1. Flow cytometric detection of circulating activated platelets in patients undergoing PTCA. Blood was sampled continuously via a heparin-coated catheter placed in the coronary sinus before vascular intervention and remaining in situ for $30 \mathrm{~min}$ after the dilatation procedure for further blood collection. Binding of fluoresceinated mAbs specific for activation-dependent platelet epitopes, including activated $\alpha \operatorname{IIb} \beta 3$ (PAC1), fibrinogen bound to $\alpha \operatorname{IIb} \beta 3$ (9F9), ligand-induced binding sites (LIBS) on $\beta 3$ (anti-LIBS1) and P-selectin, an $\alpha$-granule membrane protein expressed on the platelet surface after secretion (S12), was evaluated by one-color flow cytometry. a Flow cytometric quantification of activated platelet subpopulations. For each mAb, a gate within the fluorescence profile at baseline level (dotted line) was set to define a $2 \%$ (left panels) and 10\% (right panels) platelet subpopulation as indicated. Increase in platelet number with high fluorescence was detected in blood during PTCA (solid line). Representative histograms are shown for immunofluorescence of fluorescein isothiocyanate (FITC)-PAC1, FITC-9F9, FITC-anti-LIBS1 and FICT-S12. b Effect of PTCA on relative proportion of activated platelet subpopulations. As depicted in (a), a $\%$ platelet subpopulation with the brightest membrane fluorescence intensity at baseline was analyzed separately and quantified for relative increase in platelet number after PTCA. Bars represent mean \pm SD. p-values for increased binding of PAC1, anti-LIBS1 and 9F9 were $<0.01,<0.01$ and 0.03 , respectively. Adapted from Scharf et al. [4] and reprinted with permission of the publisher from Scharf RE, et al: Activation of platelets in blood perfusing angioplasty-damaged coronary arteries. Flow cytometry detection. Arterioscler Thromb Vasc Biol 1992:12;1475-1487.

\section{HPA-1 $\left(P l^{A}, Z w\right)$ Polymorphism of $\alpha I I b \beta 3$ (GPIIb-IIIa)}

Normal platelets contain approximately 80,000 receptor copies of integrin $\alpha I I b \beta 3$, also known as GPIIb-IIIa, $80 \%$ of which are randomly distributed and expressed on the platelet surface in its resting state, making this perhaps the most abundant receptor for adhesion and aggregation of any cell [10]. The remaining but substantial population of $\alpha \operatorname{IIb} \beta 3$ is located within the surface-connected canalicular system and within the membranes of $\alpha$-granules. These 'internal' pools of $\alpha \operatorname{IIb} \beta 3$ become surface-expressed and function-capable upon platelet activation [10]. $\alpha \mathrm{IIb} \beta 3$ can interact with fibrinogen, von Willebrand factor, fibronectin, vitronectin or thrombospondin and is the principal receptor for platelet aggregation. $\alpha \operatorname{IIb} \beta 3$ carries the human platelet antigen 1 (HPA-1) and other well-defined diallelic alloantigen systems [11]. The HPA-1 polymorphism arises from a single $\mathrm{T} \rightarrow \mathrm{C}$ nucleotide substitution at position 1565 in exon 2 of the $\beta 3$ gene, which, in turn, leads to an amino acid change at position 33 in the $\beta 3$ subunit (GPIIIa) with leucine in HPA-1a $\left(\mathrm{Pl}^{\mathrm{A} 1}\right)$ and proline in HPA-1b $\left(\mathrm{Pl}^{\mathrm{A} 2}\right)$ [12]. Importantly, the HPA-1b allele is not rare; approximately $25 \%$ of Europeans have at least 1 allele [11]. 
Fig. 2. Platelet secretion in patients with migraine accompagnée. Blood was collected at the time of a migraine attack (hatched area) in 7 patients (solid circles) and at various days after a migraine attack in 19 patients (open circles). $\beta$-thromboglobulin ( $\beta \mathrm{TG})$ was determined in platelet-free plasma as a marker of platelet secretion in vivo. Note the

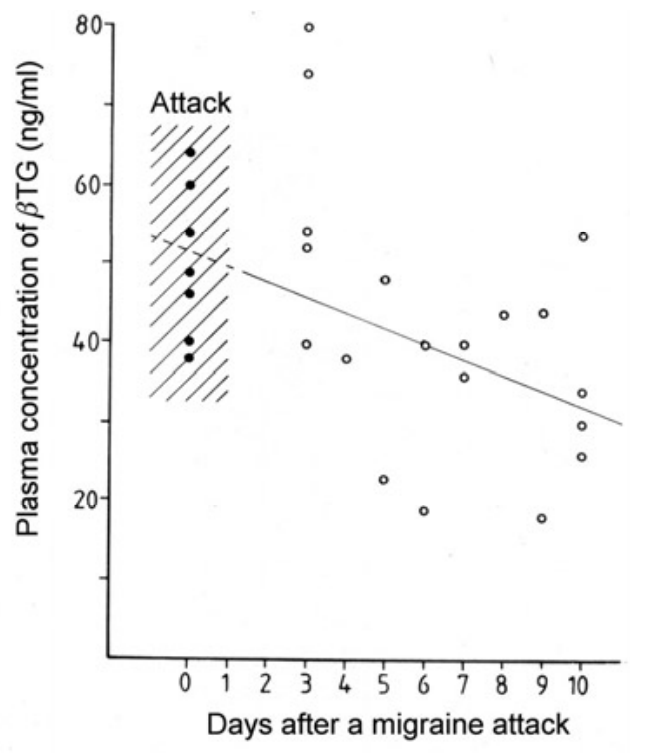

inverse relationship of the individual plasma levels of $\beta$-thromboglobulin and the interval between time of the migraine attack and blood collection $(\mathrm{n}=26, \mathrm{r}=-0.7211, \mathrm{p}<0.005)$. Adapted from Scharf [2]. Reprinted with permission of the publisher from Scharf RE. Thrombozyten und Mikrozirkulationsstörungen. Stuttgart, New York: Schattauer 1986, p 111.

\section{Polymorphisms of $\alpha 2 \beta 1$ (GPIa-IIa): $\alpha 2$ C807T and HPA-5 $(\mathrm{Br})$}

Platelets contain several receptors for collagen, including GPVI and integrin $\alpha 2 \beta 1$, also known as GPIa-IIa, both of which are important for platelet adhesion. It is now recognized that platelet adhesion to collagen requires prior activation of integrins through 'inside-out' signals generated by GPVI and reinforced by released second-wave mediators, such as ADP and thromboxane A2 [13, 14]. $\alpha 2 \beta 1$ exhibits at least 3 alleles of the $\alpha 2$ gene which are defined by 8 nucleotide polymorphisms (807C/T; 837T/C; 873G/A;1648G/A) $[15,16]$. The polymorphisms at positions 807 and 873 are silent, not altering an amino acid, while the $1648 \mathrm{G} / \mathrm{A}$ polymorphism causes an amino acid substitution (Glu $\rightarrow$ Lys) at residue 505 responsible for HPA-5 with Glu in HPA-5a (Brb) and Lys in HPA-5b $\left(\mathrm{Br}^{\mathrm{a}}\right)$. What has been of great interest, is the finding that, though the receptor is expressed at low density on the platelet surface $(1,000-3,000$ receptor copies per platelet), there is a wide, approximately 10 -fold, variation among normal individuals that can modulate platelet responses to collagen $[15,16]$. Allele 1 (807T/837T/873A/ $1648 \mathrm{G})$, also referred to as $\alpha 2807 \mathrm{~T}$, is associated with increased surface expression of $\alpha 2 \beta 1$ (high-density variant), while alleles 2 (807C/837T/873G/1648G) and 3 (807C/837C/ $873 \mathrm{G} / 1648 \mathrm{~A}$ ), also designated $\alpha 2807 \mathrm{C}$, are associated with low surface expression of the receptor [16]. Indeed, the rate of platelet attachment to type I collagen in whole blood under conditions of high shear $\left(1,500 \mathrm{~s}^{-1}\right)$ is proportional to
Table 1. Polymorphisms of platelet membrane glycoproteins. Human platelet antigens (HPA)

\begin{tabular}{|c|c|c|c|}
\hline $\begin{array}{l}\text { New } \\
\text { nomenclature }\end{array}$ & $\begin{array}{l}\text { Antigen } \\
\text { (other names) }\end{array}$ & $\begin{array}{l}\text { GP (integrin } \\
\text { subunit) }\end{array}$ & $\begin{array}{l}\text { Aminoacid } \\
\text { dimorphism }\end{array}$ \\
\hline HPA-1a & $\mathrm{Pl}^{\mathrm{A} 1}\left(\mathrm{Zw}^{\mathrm{a}}\right)$ & GPIIIa ( $\beta 3)$ & Leu $33 \rightarrow$ Pro \\
\hline HPA-1b & $\mathrm{Pl}^{\mathrm{A} 2}\left(\mathrm{Zw}^{\mathrm{b}}\right)$ & & \\
\hline HPA-2a & $\mathrm{Ko}^{\mathrm{b}}$ & GPIb $\alpha^{*}$ & Thr $145 \rightarrow$ Met \\
\hline HPA-2b & $\mathrm{Ko}^{\mathrm{a}}\left(\mathrm{Sib}^{\mathrm{a}}\right)$ & & \\
\hline HPA-3a & $\mathrm{Bak}^{\mathrm{a}}\left(\mathrm{Lek}^{\mathrm{a}}\right)$ & GPIIb ( $\alpha$ IIb) & Ile $843 \rightarrow$ Ser \\
\hline HPA-3b & $\mathrm{Bak}^{\mathrm{b}}$ & & \\
\hline HPA-4a & $\operatorname{Pen}^{\mathrm{a}}\left(\mathrm{Yuk}^{\mathrm{b}}\right)$ & GPIIIa ( $\beta 3)$ & Gln $143 \rightarrow \operatorname{Arg}$ \\
\hline HPA-4b & $\operatorname{Pen}^{\mathrm{b}}\left(\mathrm{Yuk}^{\mathrm{a}}\right)$ & & \\
\hline HPA-5a & $\operatorname{Brb}\left(\mathrm{Zy}^{\mathrm{b}}\right)$ & GPIa $(\alpha 2)^{* *}$ & Glu $505 \rightarrow$ Lys \\
\hline HPA-5b & $\mathrm{Br}^{\mathrm{a}}\left(\mathrm{Zy}^{\mathrm{a}}\right)$ & & \\
\hline
\end{tabular}

$\mathrm{GP}=$ Glycoprotein .

*TheGPIb-IX-V receptor complex is a non-integrin.

** At least 3 alleles of the $\alpha 2$ gene are defined by 8 nucleotide polymorphisms (807C/T; $837 \mathrm{~T} / \mathrm{C} ; 873 \mathrm{G} / \mathrm{A} ; 1648 \mathrm{G} / \mathrm{A})$. The $1648 \mathrm{G} / \mathrm{A}$ polymorphism is responsible for HPA-5. the density of $\alpha 2 \beta 1$ receptor copies on the platelet surface [16]. The frequency of allele 1 and allele 2 is 39 and $53 \%$, respectively, that of allele 3 is $7 \%$ [15].

\section{Clinical Studies: Role of HPA-1b and $\alpha 2$ 807TT - Pros and Cons}

\section{$H P A-1 b$}

In 1996, Weiss et al. [17] first reported on an association between the HPA-1b genotype and the risk of myocardial infarction or unstable angina. The prevalence of HPA-1b in patients admitted to a cardiac care unit was significantly higher than in hospitalized patients without coronary artery disease (CAD) ( 39.4 vs. $19.1 \%$, odds ratio $2.8, \mathrm{p}=0.01$ ). In patients whose cardiovascular event occurred prior to the age of 60 years, there was an even greater difference between cases and controls (50 vs. $13.9 \%$, odds ratio 6.2, $\mathrm{p}=0.002$ ). By contrast, no such difference in the prevalence of HPA-1b was documented when data of the Physician's Health Study were analyzed prospectively comparing patients who experienced a myocardial infarction with matched controls without cardiovascular events ( 25.2 vs. $26.4 \%, p=0.4)$ [18]. These two studies may be representative for the discrepant results published in subsequent papers [for review see 19-21]. Since then, the reasons for the conflicting findings have been a matter of ongoing debate. The same is true for the C807T polymorphism of integrin $\alpha 2 \beta 1$. 


\section{Thrombogenicity and Coronary Artery Disease}

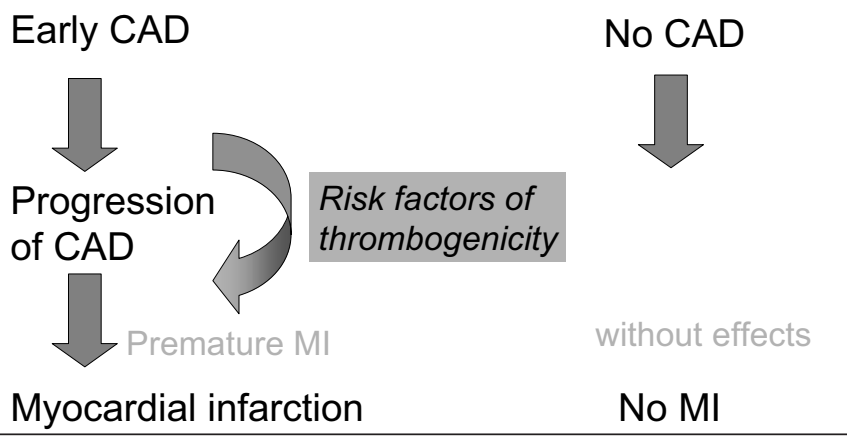

Fig. 3. Hypothetical model of how a thrombogenetic risk factor coupled with the presence of an atherosclerotic lesion becomes effective. The left panel shows progression of CAD which is accelerated in carrier patients with prothrombotic platelet receptor variants such as HPA- 1 of $\alpha \operatorname{IIb} \beta 3$ or $\alpha 2807$ TT of $\alpha 2 \beta 1$. By contrast, these prothrombotic risk factors remain without effects in the absence of an atherosclerotic burden. This model also includes the contention that different types of risk factors exist, i.e. various 'traditional' risk factors causing atherosclerosis and risk factors leading to increased platelet thrombogenicity. MI = Myocardial infarction.

\section{$\alpha 2807 T T$}

In 1999, Moshfegh et al. [22] found a significant higher prevalence of the $\alpha 2807 \mathrm{TT}$ genotype in patients with myocardial infarction as compared to healthy controls (16.4 vs. $2.6 \%$, $\mathrm{p}=0.022)$. However, this association appeared highly doubtful since the control group was rather small and the prevalence of $5.6 \%$ in the controls differed from the expected prevalence in Caucasians which is about $15 \%$ for the $\alpha 2807 \mathrm{TT}$ genotype [21]. In a large study with 2,237 male patients, no significant association of the $\alpha 2 \beta 1$ receptor variant and myocardial infarction was observed [23]. However, in subgroups of younger patients $(<62$ or $<49$ years), an increased risk for carriers of the T-allele was shown (odds ratio 1.57, $\mathrm{p}=0.004$ and 2.61, $p=0.009$, respectively). Again, views differ regarding the results of these association studies [21].

\section{Is HPA-1b a Prothrombotic Risk Determinant?}

To address this issue, we performed a retrospective study of 298 men, including 124 individuals with myocardial infarction, 83 individuals with CAD but no history of myocardial infarction, and 91 control patients who all had undergone coronary angiography [24]. The overall prevalence of HPA-1b among case patients with myocardial infarction $(23 \%)$ and control patients $(25 \%)$ did not differ $(\mathrm{p}=0.75)$. This finding confirmed the Physician's Health Study [18]. However, a further analysis of our data revealed that the prevalence of HPA- $1 \mathrm{~b}$ was related to the patients' age and dependent on the time after myocardial infarction with highest values in younger patients ( $\leq 60$ years) with myocardial infarction and patients with recent onset ( $<1$ year) myocardial infarction ( 45 vs. $23 \%$ in controls, odds ratio $2.0, p=0.007$ ). Thus, we could document a significant association between the HPA-1b genotype and acute or recent onset myocardial infarction and thereby confirm the observation of Weiss et al. [17]. Moreover, we found that patients with CAD who are carriers of the HPA-1b allele experience a myocardial infarction earlier in life than patients who are HPA-1b-negative [24]. The findings of our study have led to the following preliminary conclusion: The HPA- $1 \mathrm{~b}$ genotype of integrin $\alpha \operatorname{IIb} \beta 3$ is not a risk factor for atherosclerosis but a risk factor for arterial thrombosis.

\section{Working Hypothesis: HPA-1b is a Risk Factor of Increased Thrombogenicity}

Based on this conclusion, we hypothesized that HPA- $1 \mathrm{~b}$ is a prothrombotic risk determinant which requires the presence of an atherosclerotic lesion to become effective. Thus, unlike conventional risk factors, HPA-1b does not represent a risk factor for CAD itself but appears to be associated with increased platelet thrombogenicity. This contention provides an explanation for some of the conflicting results presented in various clinical association studies regarding the role of the HPA-1 polymorphism of integrin $\alpha \operatorname{IIb} \beta 3$ in patients with CAD. Along with our hypothesis, it can be anticipated that even in prospective studies (e.g. the Physician's Health Study [18]), the effect of a polymorphism coupled with the presence of CAD will provide no difference in the prevalence of HPA$1 \mathrm{~b}$ between a patient group with myocardial infarction and a control group, since the genetically determined receptor variant is not associated with an increased rate of myocardial infarction but a premature onset of myocardial infarction. Our hypothesis is illustrated schematically in figure 3 . Along with this contention, there are several implications for future investigations: i) Prospective studies with precisely defined clinical endpoints are required. ii) Any selection bias due to recruitment of patients, controls or both and any post-data collection search for significance must be excluded by following strictly predefined criteria. iii) Apart from studies with a case control design, analyses using a case-only design are required. iv) Despite their interaction and interdependency in atherothrombotic disorders, a clear distinction has to be made between risk factors causing arteriosclerosis and those leading to increased thrombogenicity and, thus, accelerating thrombotic occlusion of already diseased arteries.

\section{Prospective Study}

We prospectively determined the HPA- 1 genotype in 261 consecutive patients prior to saphenous-vein coronary artery by- 
Fig. 4. Distribution of age at onset of myocardial infarction in relation to the HPA-1 ( $\beta 3 \mathrm{C} 1565 \mathrm{~T})$ and $\alpha 2$ C807T polymorphisms of $\alpha \mathrm{IIb} \beta 3$ (GPIIb-IIIa) and $\alpha 2 \beta 1$ (GPIa-IIa), respectively. The plots show the proportion of patients without myocardial infarction in the subgroup of patients with 1- and 2-vessel disease and recent onset myocardial infarction ( $<1$ year). The age at onset of myocardial infarction is referred to as event time, $\mathbf{a}$ in relation to HPA-1, $\mathbf{b}$ in relation to $\alpha 2$ (GPIa) C807T. The median age at onset of myocardial infarction was 54.0 years in HPA-1b-positive patients, 59.2 years in the HPA-1b-negative patients ( $\mathrm{p}<0.006$ by log-rank test), 52.5 years in carriers of the $\alpha 2807 \mathrm{TT}$ genotype and 58.8 years in carriers of the $\alpha 2807 \mathrm{CC}$ or $\alpha 2$ $807 \mathrm{CT}$ genotype ( $\mathrm{p}<0.006$ by log-rank test). Adapted from Zotz et al. [27] and reprinted with permission of the publisher from Zotz et al: Association of polymorphisms of platelet membrane integrins $\alpha_{2} \beta_{3}$ (HPA- $1 \mathrm{~b} / \mathrm{Pl}^{\mathrm{A} 2}$ ) and $\alpha$ II $(\alpha 2807$ TT) with premature myocardial infarction. J Tromb Haemost 2005;3:1522-1529.

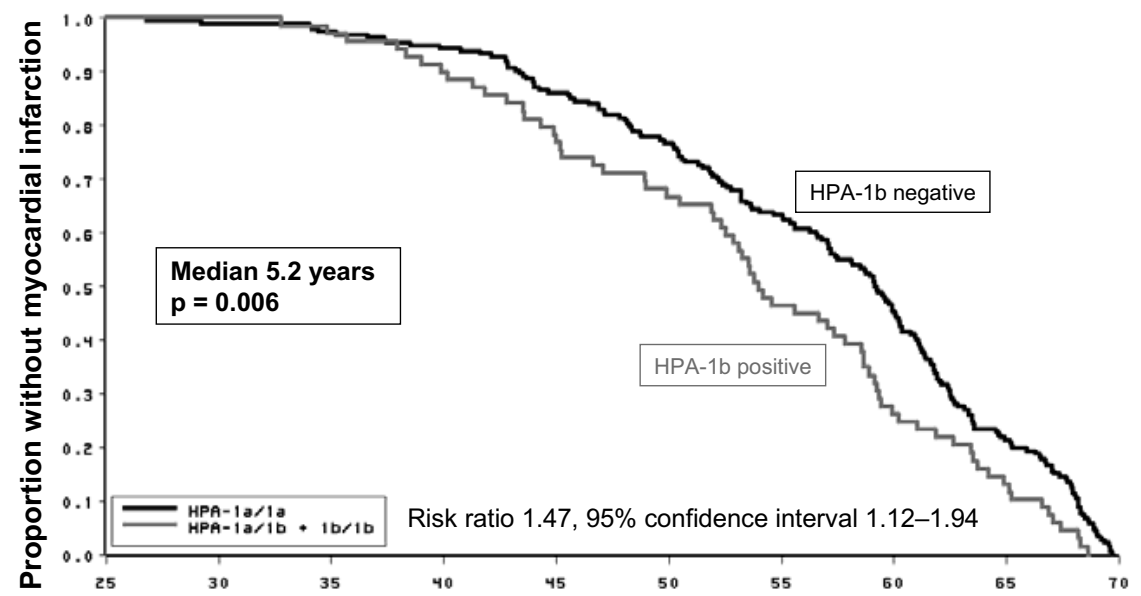

a Age at onset of myocardial infarction, years

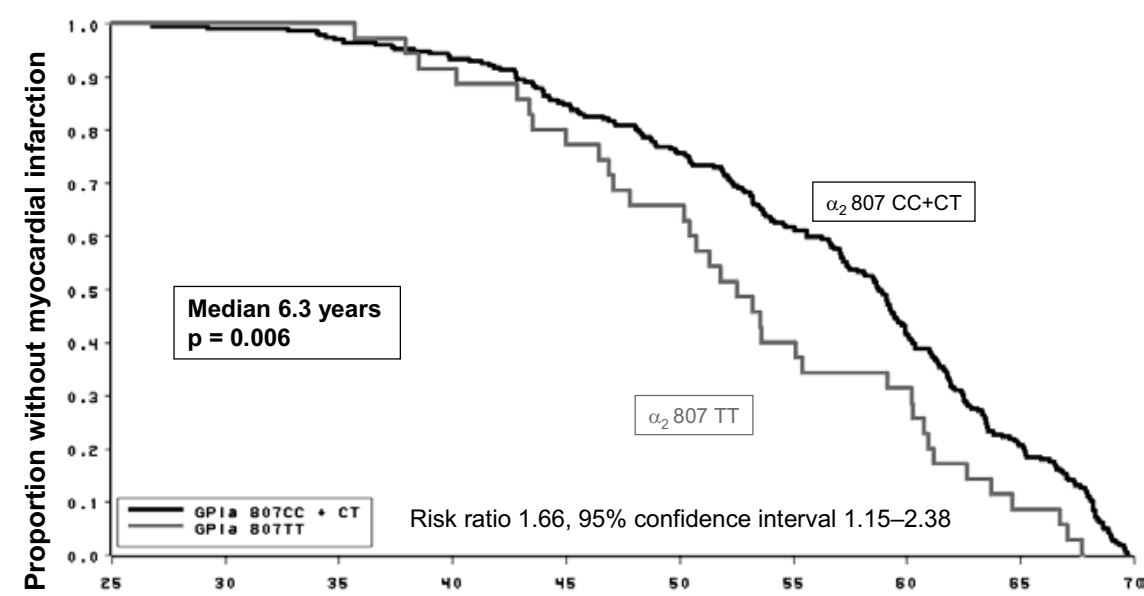

b

Age at onset of myocardial infarction, years pass grafting and performed a follow-up over 1 year [25]. Among patients with bypass occlusion, myocardial infarction or death more than 30 days after surgery, the prevalence of HPA-1b was significantly higher than among patients without postoperative complications (60 vs. $24 \%$, odds ratio 4.7 , $\mathrm{p}<0.05)$. Using a stepwise logistic regression analysis with the variables HPA-1b, age, sex, body mass index, smoking, hypertension, diabetes mellitus, cholesterol and triglyceride concentration, only HPA-1b had a significant association with bypass occlusion, myocardial infarctions or death after bypass surgery (odds ratio 4.7, $\mathrm{p}=0.019$ ) [25]. These results are compatible with our hypothesis that HPA-1b is a risk factor for increased thrombogenicity. In the opinion of others [26], this study is remarkable for 2 reasons: i) It is the only prospective HPA- 1 b study to examine the outcome after bypass surgery so far, and ii) the significant association between HPA-1b and poor outcome shows one of highest odds ratios ever reported in any study.

\section{Premature Myocardial Infarction in Carriers of HPA-1b and $\alpha 2$ 807TT with Coronary Artery Disease}

Our hypotheses would be further supported by demonstrating that i) no association between CAD and the prothrombotic receptor variants exists, and that ii) patients with CAD carrying the critical genotypes experience a myocardial infarction earlier in life. To address these items, we genotyped 3,261 extensively characterized and well-documented patients of the prospective Ludwigshafen Risk and Cardiovascular Heath (LURIC) project, including 1,175 survivors of a myocardial infarction, 1,211 individuals with CAD but no history of myocardial infarction, 571 control patients without angiographically detectable CAD and, in addition, 793 blood donors [27]. All subgroups and exclusion criteria were specified prior to the initiation of data analysis based on the results of our previous study in another population [24].

In a case-control design, the prevalence of HPA- $1 \mathrm{~b}$ and $\alpha 2$ 
Fig. 5. Principle of the technique and equipment to study platelet adhesion onto thrombogenic surfaces under flow conditions. Prior to the experiment, platelets in whole blood are stained with a fluorophor. Adhesive substrates coated onto glass coverslips form the lower surface of the flow chamber (a) which is mounted on a laser scanning confocal microscope (b). Instead of the syringe (shown in the foreground), a syringe pump is used to aspirate blood through the chamber at a constant flow rate.
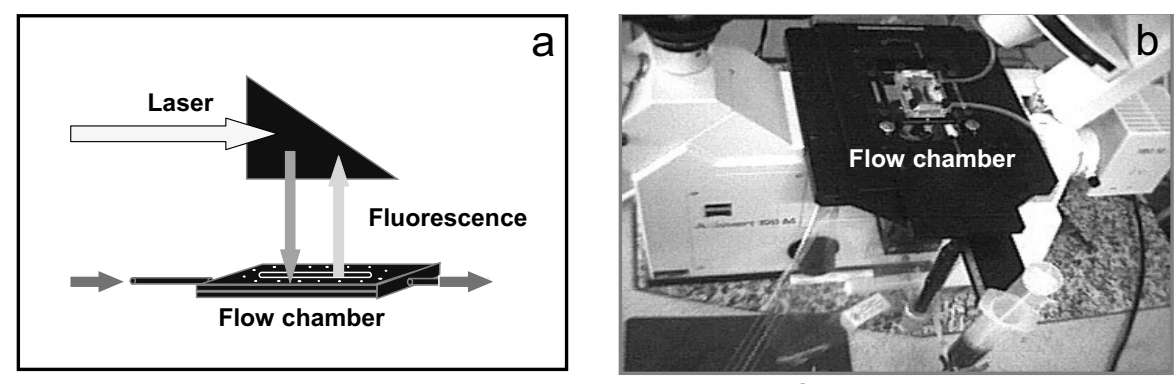

Laser Scanning Microscope
807TT genotypes did not differ significantly between the patient groups with CAD or myocardial infarction and patient controls or blood donors. By contrast, using a multivariate case-only design, it was found that the median age of onset of myocardial infarction was 5.2 years earlier $(\mathrm{p}=0.006)$ in carriers of the HPA-1b allele and 6.2 years earlier in carriers of the $\alpha 2$ 807TT genotype in 264 survivors of myocardial infarction of recent onset (fig. 4). A significant interaction with conventional risk factors, such as hypercholesterolemia, smoking, diabetes mellitus, hypertension and hyperfibrinogenemia was excluded. These results document that HPA-1b and $\alpha 2$ 807TT are associated with premature manifestation of myocardial infarction but not with CAD itself and support the hypothesis that distinct integrin genotypes can lead to increased platelet thrombogenicity. As the effects of the platelet receptor polymorphisms are coupled to the presence of CAD, it is likely that the quality of the atherosclerotic lesion (e.g. plaque instability) is decisive as a trigger. The remarkable similarity in which both genetically unlinked markers behave supports our hypothesis that both receptor variants, HPA- $1 \mathrm{~b}$ of $\alpha \mathrm{IIb} \beta 3$ and $\alpha 2807 \mathrm{TT}$ of $\alpha 2 \beta 1$, are prothrombotic. Thus, in conclusion, both genotypes, HPA-1b and $\alpha 2807 \mathrm{TT}$, are risk factors for myocardial infarction in patients with already existing atheromatous burden, but not risk factors for the development of atheroma.

\section{Platelet Functional Characteristics by HPA-1b Genotype}

The results of positive clinical association studies between platelet polymorphisms and CAD require characterization of the phenotypes. What are the functional consequences of integrin receptor variants if there are any?

\section{Fibrinogen Binding}

We have used flow cytometry and FITC-conjugated human fibrinogen to study the ligand binding function of integrin $\alpha I I b \beta 3$ upon platelet stimulation with increasing concentrations of ADP comparing HPA-1a/1a with HPA-1a/1b and HPA-1b/1b genotypes [28]. At ADP concentrations of $0.5 \times$ $10^{-6} \mathrm{~mol} / \mathrm{l}$ and $10^{-6} \mathrm{~mol} / \mathrm{l}$, specific binding of fibrinogen to HPA-1b-positive platelets was significantly higher than to
HPA-1b-negative platelets $(\mathrm{p}<0.009$ and $\mathrm{p}<0.034$, respectively). This difference was not related to the receptor density of $\alpha$ IIb $\beta 3$ or platelet volume. Our findings were confirmed by Goodall et al. [29] but not by others [30].

\section{Aggregation and Activation Studies}

In a large study enrolling 1,422 individuals, a significantly lower epinephrine threshold concentration was required to induce aggregation in HPA-1b-positive platelets [31, 32]. Likewise, when neoantigens and neoepitopes such as P-selectin and LIBS1 were determined, HPA-1b-positive platelets had a higher sensitivity than HPA-1a/1a platelets in response to lowdose ADP or epinephrine [33]. We found a significantly increased surface expression of P-selectin, LIBS1, LAMP3, $\alpha \operatorname{IIb} \beta 3$-bound fibrinogen and activated $\alpha \operatorname{II} \beta 3$ upon stimulation with low-dose ADP in HPA-1b-positive platelets as compared to the homozygous HPA-1a genotype [34]. Aspirin inhibition also varies by HPA-1 genotype [33]. Thus, HPA-1b-positive platelets are hyperreactive and reveal an altered sensitivity to antiplatelet agents. However, in contrast to the results of Michelson et al. [33], we did not find significant differences between HPA-1a/1a, HPA-1a/1b and HPA-1b/1b platelets of patients with stable CAD (132 men, 45 women, aged $64 \pm 0.9$ years) or healthy individuals (45 men, 17 women, aged $38 \pm$ 1.5 years) with respect to in vitro inhibition of abciximab, tirofiban or eptifibatide [35].

In summary, functional characterization of HPA-1b-positive platelets argues for a prothrombotic phenotype. However, the findings reported from several laboratories are by no means uniform and consistent. To address this problem in further detail, we have used an established model to study platelet adhesion and thrombus formation under conditions simulating atherosclerotic lesions and arterial flow [36-38].

\section{Modulation of Platelet Adhesion, Aggregation and Thrombus Formation by Integrin Receptor Variants under Arterial Flow Conditions}

The experimental design and the principle of the technique and equipment used to study platelet adhesion onto thrombogenic matrices at defined share rates are depicted in figure 5. 


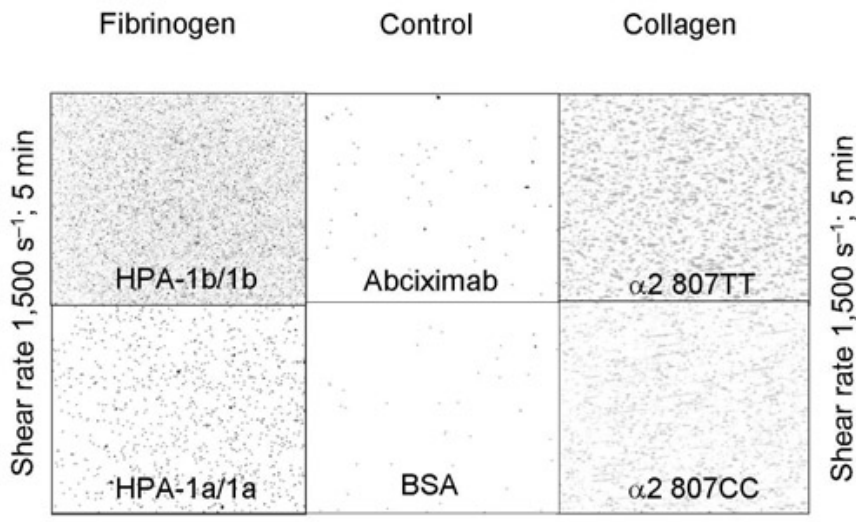

Fig. 6. Real-time observation of platelet adhesion onto surface-bound fibrinogen, type I collagen or BSA under flow conditions. Substrates coated onto glass coverslips were placed in a parallel plate flow chamber that produces a variable wall shear rate. Blood containing PPACK as anticoagulant and treated with the fluorescent dye mepacrine for platelet visualization was perfused through the chamber for $5 \mathrm{~min}$ at a shear rate of $1,500 \mathrm{~s}^{-1}$. Each single frame image corresponds to an area of $980 \times 980 \mu \mathrm{m}$. The 3 top panels show adhesion of platelets with the putative prothrombotic genotypes, i.e. HPA-1b/1b of integrin $\alpha \operatorname{IIb} \beta 3$ or $\alpha 2807 \mathrm{TT}$ of integrin $\alpha 2 \beta 1$, onto immobilized fibrinogen (left frame) or type I collagen (right frame), respectively. The 3 bottom panels show adhesion of platelets with the uncritical 'wild-type' receptor form, i.e. HPA-1a/1a or $\alpha 2807 \mathrm{CC}$, under identical experimental conditions. The 2 middle panels represent control experiments with HPA-1b/1b platelets. Addition of abciximab, an $\alpha \operatorname{IIb} \beta 3$ blocking mAb, at a final concentration of $4 \mu \mathrm{g} / \mathrm{ml}$ caused $>99 \%$ inhibition of platelet adhesion onto fibrinogen. No platelet adhesion was detected when coverslips had been coated with BSA. Note the presence of platelet aggregates (thrombi) on the collagen surface. These images are representative of the results obtained in 60 experiments with blood from healthy donors.

In brief, whole blood from healthy individuals, anticoagulated with either PPACK, a direct thrombin inhibitor, or, depending on the type of experiment, trisodium citrate was incubated with mepacrine to render platelets fluorescent. Blood was aspirated with a syringe pump (Harvard Apparatus Inc., Boston, MA, USA) through a parallel-plate rectangular perfusion chamber (flow path height: $80 \mu \mathrm{m}$ ) at a flow rate of 160 or 480 $\mu \mathrm{l}$ per min to provide wall shear rates of 500 or $1,500 \mathrm{~s}^{-1}$, respectively. Prior to perfusion, glass cover slips were coated with human fibrinogen, fibrillar type I collagen or extracellular matrix secreted and deposited by growing endothelial cells [37]. For corresponding control experiments, bovine serum albumin (BSA) or receptor blocking mAbs were used. The chamber was mounted on a Zeiss Axiovert 100M/LSM 510 invert laser scanning confocal microscope (Carl Zeiss, Oberkochen, Germany). Direct visualization of adherent platelets, aggregate or thrombus formation were either performed by real time epifluorescence videomicroscopy (Zeiss Axiovert 100; Sony Progressive 3CCD) or by confocal microscopy (Zeiss LSM 510). For image processing and quantification of adherent platelets and thrombus formation, special
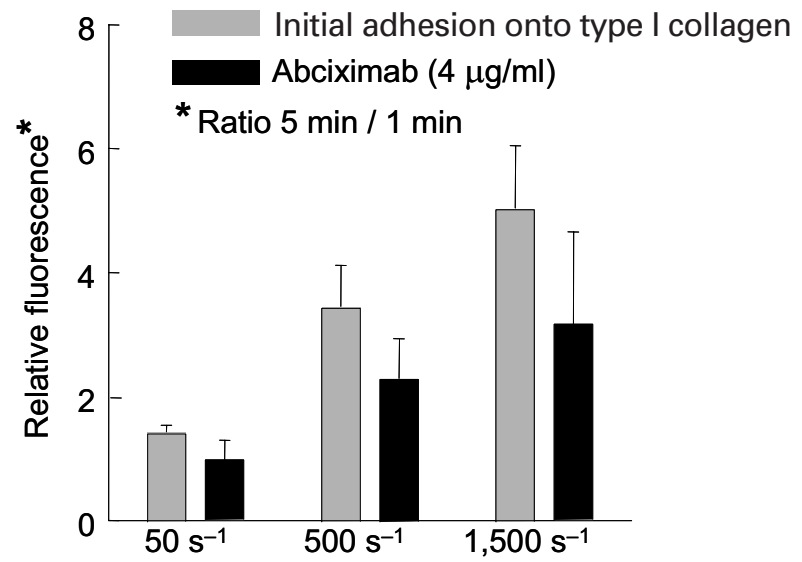

Fig. 7. Synergy of integrins $\alpha 2 \beta 1$ and $\alpha \operatorname{IIb} \beta 3$ to promote stable adhesion, aggregate formation and thrombus growth. Platelets in whole blood anticoagulated with trisodium citrate were incubated with mepacrine and allowed to adhere onto type I collagen at wall shear rates of $50 \mathrm{~s}^{-1}, 500 \mathrm{~s}^{-1}$ or $1,500 \mathrm{~s}^{-1}$ for $5 \mathrm{~min}$ in the absence (gray columns) or presence (black columns) of abciximab at a final concentration of $4 \mu \mathrm{g} / \mathrm{ml}$. Absolute fluorescence intensity corresponding to the number of platelets attached per defined area and expressed as arbitrary (pixel) units was recorded at 1 and $5 \mathrm{~min}$. Fluorescence intensity recorded at $1 \mathrm{~min}$ corresponds to platelet adhesion onto type I collagen, while data obtained at $5 \mathrm{~min}$ are representative of platelet aggregate or thrombus formation mediated by $\alpha$ IIb $\beta 3$ in the absence of abciximab. The amount of platelets attached is expressed as relative fluorescence defined as ratio of absolute fluorescence at 5 and $1 \mathrm{~min}$. Bars represent mean \pm SD of 5 five experiments with blood from different donors.

software packages were available (MetaMorph, Molecular Devices, Sunnyvale, CA, USA; Image J, National Institute of Health, Bethesda, MD, USA).

Using these experimental procedures and techniques, a striking difference in platelet adhesion rates onto fibrinogen or type I collagen was documented between homozygous HPA$1 \mathrm{~b}$ and HPA- $1 \mathrm{a}$ genotypes of $\alpha \operatorname{IIb} \beta 3$ or $\alpha 2$ 807TT and $\alpha 2807 C \mathrm{C}$ of $\alpha 2 \beta 1$ at wall shear rates within the range of arteriolar flow (fig. 6). This finding is entirely in agreement with the previously proposed hypothesis derived from clinical association studies demonstrating prothrombotic effects of both integrin receptor variants, HPA-1b and $\alpha 2$ 807TT. At shear rates relevant for hemostasis in arterioles as well as thrombosis in atherosclerotic arteries, $\alpha \operatorname{IIb} \beta 3$ and $\alpha 2 \beta 1$ are prominent players in mediating stable platelet adhesion and aggregation [37]. The role of $\alpha \operatorname{IIb} \beta 3$ as a key receptor for adhesive protein, notably fibrinogen and von Willebrand factor, that are involved in linking platelets to one another is well established [38]. As shown previously by Savage et al. [37], integrin $\alpha 2 \beta 1$ acts in concert with both the glycoprotein Ib-IX-V complex and its binding to immobilized von Willebrand factor as well as $\alpha \operatorname{IIb} \beta 3$ to promote stable adhesion and activation of platelets. This synergistic effect of the 3 key receptors with regard to thrombogenesis under arterial flow conditions was 


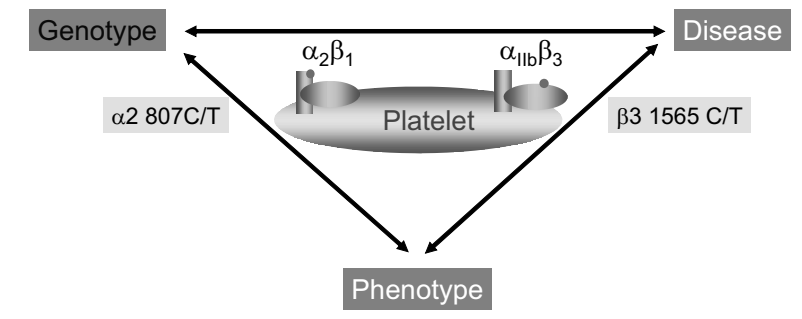

Fig. 8. Genotype-to-phenotype and phenotype-to-disease correlation The arrows depicted in this triangle scheme suggest a causal interaction which is currently hypothetical. A clear distinction between laboratory phenotype and clinical phenotype, i.e. disease, must be made.

confirmed by our experiments (fig. 6). More importantly, adhesion and aggregate formation of platelets with combined critical genotypes of $\alpha \operatorname{IIb} \beta 3$ and $\alpha 2 \beta 1$, i.e. HPA- $1 b / 1 b$ and $\alpha 2$ 807TT, were significantly increased compared to platelets with HPA-1a/1a and $\alpha 2807 \mathrm{CC}(\mathrm{p}=0.02)$. Thus, it is likely that the synergistic action of both integrins provides a reinforcement which is leading to increased thrombogenisis of their receptor variants but is inhibited in the presence of $\alpha \operatorname{IIb} \beta 3$ blocking mAbs (fig. 7).

In another series of experiments, the dynamics of thrombus formation was evaluated. For 3-dimensional analysis of thrombus growth over time ('4-D' imaging ), a series of stacks, i.e. 30 confocal optical sections, from the bottom to the apex of the forming platelet thrombus, were obtained every $25 \mathrm{~s}$ with a 488 -nm laser and a scanning time of $<500 \mathrm{~ms}$ on an area of $26,450 \mu \mathrm{m}^{2}$. Images corresponding to an area of $0.202 \mu \mathrm{m}^{2}$ were analyzed by a 'voxel'-based procedure, whereby a voxel is defined by a volume of $0.202 \mu \mathrm{m}^{3}\left(0.45 \mu \mathrm{m}^{2} \times 0.45 \mu \mathrm{m}^{2} \times\right.$ $1 \mu \mathrm{m}$ ). For calibration, fluorescent beads (Invitrogen, Carlsbad, CA, USA) were used, and the volume corresponding to a $1.0 \mu \mathrm{m}$ thick stack was calculated pursuant to the voxel technique. With citrate-anticoagulated blood at an initial wall shear rate of $500 \mathrm{~s}^{-1}$ and type I collagen under otherwise identical experimental conditions, as described above, thrombus volume reached a maximum after $420 \mathrm{~s}$. Thrombus progression occurred in a 2-step way with an apical growth (height extension) at the interval of 220 and $300 \mathrm{~s}$, and a further growth in the plane section at the interval of 300 to $420 \mathrm{~s}$ after perfusion [39]. Prolonged perfusion resulted in markedly abnormal flow patterns due to thrombus growth and increased shear rates $\left(>500 \mathrm{~s}^{-1}\right)$. Interestingly, the HPA-1 polymorphism of $\alpha$ IIb $\beta 3$ had a dramatic effect on thrombus growth. Thus, when comparing blood from homozygous carriers of HPA-1b $(\mathrm{n}=8)$ and HPA-1a $(\mathrm{n}=8)$, thrombus formation and progression occurred more rapidly with HPA-1b than with HPA-1a platelets, resulting in significantly larger thrombi from HPA$1 \mathrm{~b}$ than from HPA-1a individuals $(\mathrm{p}=0.001)$ [39].
In summary, the voxel-based analysis of thrombus formation and progression under flow conditions can detect phenotypic differences related to the HPA-1 polymorphism of integrin $\alpha I I b \beta 3$. Specifically, our results confirm in the experimental setting that HPA-1b is a thrombogenic receptor variant.

\section{Adhesion of Transfected Cells Expressing HPA-1b or HPA-1a of $\alpha$ llb $\beta 3$}

A general problem of such studies in vitro, simulating physiological and pathological flow conditions, is the need for anticoagulation and, even more crucial, the notorious variability of platelet function assays. This is related, at least in part, to interindividual variability. To overcome these difficulties and to circumvent interindividual variability, we and others [40, 41] have generated transfected Chinese hamster ovary $(\mathrm{CHO})$ cells expressing either HPA-1a or HPA- 1 b of $\alpha \operatorname{IIb} \beta 3$. We have examined these transfectants in the flow system described above and performed displacement experiments. Briefly, $\mathrm{CHO}$ cells were allowed to adhere onto immobilized fibrinogen at low shear rates $\left(50-100 \mathrm{~s}^{-1}\right)$ and were then stepwise exposed to continuously increasing wall shear rates (up to 500 $\mathrm{s}^{-1}$ ). Under these experimental conditions, HPA-1b cells were significantly more restistant to shear stress than the HPA-1a isoform. This observation is in agreement with results of others. Thus, Vijayan et al. [40, 41] reported that significantly more HPA-1b-transfected CHO cells bound to immobilized fibrinogen in an $\alpha I$ Ilb $\beta 3$-dependent manner than did HPA-1a cells. Such differences are likely to reflect changes in the nature or the efficiency of outside-in signals that are generated when $\alpha I I b \beta 3$ encounters a thrombogenic substrate. Indeed, very recent findings demonstrate that the HPA-1b genotype of $\alpha I I b \beta 3$ enhances outside-in signaling in human platelets by activating the serine/threonine phosphorylation of extracellular signal-regulated kinase and myosin light-chain [42]. In summary, the HPA-1b isoform of integrin $\alpha \mathrm{IIb} \beta 3$ confers a prothrombotic phenotype in human platelets and transfected CHO cells.

\section{Genotype-to-Phenotype and Phenotype-to-Disease Correlation}

One of the attractive aspects of positive epidemiologic association studies between platelet receptor polymorphisms and CAD is the biologic plausibility that variations in a critical hemostatic molecule will modify its function and induce a prothrombotic state [43, 44]. Such a contention assumes that a genetically determined receptor variant is causative for the disease and not merely linked to the causative gene. Indeed, as discussed in detail above, the functional characterization of the integrin receptors $\alpha \operatorname{IIb} \beta 3$ and $\alpha 2 \beta 1$ now provide a plethora of experimental data documenting a prothrombotic pheno- 
type of both variants, HPA-1b and $\alpha 2$ 807TT. Moreover, there are several indications that the Pro33 substitution in the $\beta$ subunit of $\alpha \operatorname{IIb} \beta 3$ that results from a single nucleotide polymorphism (SNP) modulates ligand binding function and outside-in signaling of platelets and transfected cell lines. However, there is a number of limitations regarding a causative association of a polymorphism and its functional consequences.

First, there is an apparent importance of lifelong risk interactions between environment and genetic polymorphisms [45]. While appreciable progress with regard to venous thromboembolic disorders has been made in terms of functional and clinical consequences of certain polymorphisms (e.g. G1691A mutation in the factor $\mathrm{V}$ gene), the development of arterial disease and its thrombotic complications (atherothrombosis) is less well understood. This is attributed to the complexity of the processes involved in vascular disease, in particular, the lack of knowledge about the interactions between environment and genetic polymorphisms [45].

Second, some of the problems in identifying causal genetic markers of arterial disease are related to the difficulties associated with the precise definition of the clinical phenotype under study. For example, there is plurality in clinical endpoints (e.g. myocardial infarction, unstable angina, CAD, progression of arterial disease or stroke) and, as evident from some of the clinical studies, these endpoints have been selected in a post-data collection search for significance [45]. In this context, the autopsy study by Mikkelson et al. [46] is of particular relevance reporting that the prevalence of HPA-1b was higher in individuals with myocardial infarction caused by thrombosis than in those without thrombosis ( $p<0.001$ unadjusted, $\mathrm{p}<0.005$ adjusted). Interestingly, these autopsy findings are consistent with the model depicted in figure 3 and hypothesized in our initial publication on HPA-1b [24].

Third, the importance of heritability of risk factors has generally not been fully appreciated. Moreover, the apparent paradox of a firm relationship between gene and protein and, even more striking, between protein and disease, but inconsistent gene-to-disease relationships, must be related to the quantitative contribution of heritability to the laboratory phenotype, e.g. the density of receptor expression on the platelet surface (fig. 8) [45]. However, the relationship between platelet receptor genotype and disease is currently unknown. Thus, the study of population genetics of polygenic disorders, such as ar- terial thrombotic disease, would require prior knowledge of i) the relationship between receptor density and disease, ii) the degree of heritability of variance in receptor density and iii) the genetic determinants of heritability [45].

Fourth, it is highly unlikely that single genetic polymorphisms can be the sole determinants of arterial disease. In this context, the distinction between risk factors leading to atherosclerosis and those causing increased platelet thrombogenicity, as proposed by our own findings [24, 25, 27], is an appealing hypothesis which, however, requires future detailed examination. Thus, further studies should be designed specifically to investigate the interactions between genetic polymorphisms of platelet receptors or other hemostatic components and acquired risk factors. It is conceivable that hemostatic genes have to interplay with other genetic or environmental effects before they can influence disease progression.

In conclusion, despite the significant progress that has been made within the last decade, we are far away from having established the genetic basis for arterial vascular disorders. There is a clear need for well-designed, large, prospective genetic epidemiological studies. In parallel to such clinical investigations, further in vitro studies of functional consequences of inherited traits are required to provide a sound rationale for risk-adapted prophylaxis and selective pharmacological strategies that will be beneficial to patients.

\section{Acknowledgements}

This work was supported by grants of the Deutsche Forschungsgemeinschaft (Scha 358/3-1 and Sonderforschungsbereich 612 'Molecular analysis of cardiovascular functions and dysfunctions', TPB2 'Modulation of platelet thrombogenicity through genetically determined variants of platelet integrins'). Additional support was provided by the Biological Medical Research Center, Heinrich Heine University, Düsseldorf, Germany. We thank Prof. Zaverio M. Ruggeri, The Scripps Research Institute, La Jolla, CA, USA, for providing mAbs (LJ-P4, LJ-CP8, LJ-Ib $\alpha$ ) and purified human fibrinogen, Prof. Sanford J. Shattil and Prof. Mark H. Ginsberg, Department of Medicine, University of California San Diego, La Jolla, CA, USA, for PAC1 and anti-LIBS1, Prof. Volker Aurich and Dr. Andreas Beck, Institue of Informatics, Heinrich Heine University Düsseldorf, for their help with computation and image analysis. We express particular gratitude to Dr. Volker Stodt, Dr. Robert Loncar and Jan Peveling, M.D. student, for their invaluable experimental work including thrombus volume analysis. The technical assistance of Elisabeth Kirchhoff, Beate Maruhn-Debwoski, Uta Vandercappelle and Bianca Weingart is also acknowledged.

\section{References}

1 Fitzgerald DJ, Roy L, Catella F, FitzGerald GA: Platelet activation in unstable coronary disease. N Engl J Med 1986;315:983-989.

2 Scharf RE: Thrombozyten und Mikrozirkulationsstörungen. Stuttgart, New York, Schattauer, 1986

3 Fuster V, Badimon L, Badimon JJ, Chesbro JH: The pathogenesis of coronary artery disease and the acute coronary syndromes (1). N Engl J Med 1992;326:242-250.
4 Scharf RE, Tomer A, Marzec UM, Teirstein PS, Ruggeri ZM, Harker LA: Activation of platelets in blood perfusing angioplasty-damaged coronary arteries. Flow cytometric detection. Arterioscler Thromb Vasc Biol 1992;12:1475-1487.

5 Hannington E, Jones RJ, Amess JAL, Wachowicz B: Migraine: a platelet disorder. Lancet 1981;ii:720.

6 Davies JA, McNicol GP: Detection of a prethrombotic state; in Bloom AL, Thomas DP (eds): Haemostasis and Thrombosis. Edinburgh, London, Churchill Livingstone, 1981, pp 593-609.
7 Yee DL, Sun CW, Bergeron AL, Dong JF, Bray PF: Aggregometry detects platelet hyperreactivity in healthy individuals. Blood 2005;106:2723-2729.

8 Trip MD, Cats VM, van Capelle FJL, Vreeken J: Platelet hyperreactivity and prognosis in survivors of myocardial infarction. N Engl J Med 1990;322: 1549-1554.

9 Mammen EF: Sticky platelet syndrome. Semin Thromb Hemost 1999;25:361-365. 
10 Scharf RE: Molecular basis and clinical aspects of hereditary megakaryocyte and platelet membrane glycoprotein disorders. Hämostaseologie 1996;16: 114-138.

11 Kunicki TJ, Newman PJ: The molecular immunology of human platelet proteins. Blood 1992;80:13861404

12 Newman PJ, Derbes RS, Aster RH: The human platelet alloantigens, $\mathrm{Pl}^{\mathrm{A} 1}$ and $\mathrm{Pl}^{\mathrm{A} 2}$, are associated with a leucine 33/proline 33 amino acid polymorphism in membrane GPIIIa, and are distinguishable by DNA typing. J Clin Invest 1989;83 1778-1781

13 Nieswandt B, Watson SP: Platelet-collagen interaction: is GPVI the central receptor? Blood 2003;102: 449-461.

14 Sarratt KL, Chen H, Zutter MM, Santoro SA Hammer DA, Kahn ML: GPVI and $\alpha_{2} \beta_{1}$ play independent critical roles during platelet adhesion and aggregate formation to collagen under flow. Blood 2005;106:1268-1277.

15 Kunicki TJ, Kritzik M, Annis DS, Nugent DJ: Hereditary variation in platelet alpha2 beta1 density is associated with two silent polymorphisms in the alpha2 coding sequence. Blood 1997;89:19391943

16 Kritzik M, Savage B, Nugent DJ, Santoso S, Ruggeri ZM; Kunicki TJ: Nucleotide polymorphisms in the alpha 2 gene define multiple alleles that are associated with differences in platelet alpha2 beta1 density. Blood 1998;92:2382-2388.

17 Weiss EJ, Bray PF, Tayback M, Shulman SP, Kickler TS, Becker LC, Weiss JL, Gerstenblith G, Goldschmidt-Clermont PJ: A polymorphism of a platelet glycoprotein receptor as an inherited risk factor for coronary thrombosis. N Engl J Med 1996; 334:1090-1094.

18 Ridker PM, Hennekens CH, Schmitz C, Stampfer $\mathrm{M}$, Lindpaintner $\mathrm{K}$ : $\mathrm{Pl}^{\mathrm{A} 1 / \mathrm{A} 2}$ polymorphism of platelet glycoprotein IIIa and the risks of myocardial infarction, stroke, and venous thrombosis. Lancet 1997;349:385-388.

19 Zhu MM, Weedon J, Clark LT: Meta-analysis of the association of platelet glycoprotein IIIa $\mathrm{Pl}^{\mathrm{A} 1 / \mathrm{A} 2}$ polymorphism with myocardial infarction. Am J Cardiol 2000;86:1000-1005.

20 Di Castelnuovo A, de Gaetano G, Donati MB Platelet glycoprotein receptor IIIa polymorphism $\mathrm{Pl}^{\mathrm{A} 1 / \mathrm{A} 2}$ and coronary risk: a meta-analysis. Thromb Haemost 2001;85:626-633.

21 Zotz RB, Scharf RE: Platelet receptor polymorphisms and their role in cardiovascular disease. J Lab Med 2002;26:584-593.

22 Moshfegh F, Wuillemin WA, Redondo M, Lämmle B, Beer JH, Liechti-Gallati S, Meyer BJ: Association of two silent polymorphisms of platelet glycoprotein Ia-IIa receptor with risk of myocardial infarction: a case-control study. Lancet 1999;353. 351-354.
23 Santoso S, Kunicki TJ, Kroll H, Haberbosch W, Gardemann A: Associations of the platelet glycoprotein Ia C807T gene polymorphism with nonfatal myocardial infarction in younger patients. Blood 1999:93:2449-2453.

24 Zotz RB, Winkelmann BR, Nauck M, Giers G, Maruhn-Debowski B, März W, Scharf RE: Polymorphism of platelet membrane glycoprotein IIIa: Human platelet antigen 1b (HPA- $1 \mathrm{~b} / \mathrm{Pl}^{\mathrm{A} 2}$ ) is an inherited risk factor for premature myocardial infarction in coronary artery disease. Thromb Haemost 1998;79:731-735.

25 Zotz RB, Klein M, Dauben HP, Moser C, Gams E, Scharf RE: Prospective analysis of patients after coronary-artery bypass grafting: Platelet GPIIIa polymorphism (HPA-1/Pl ${ }^{\mathrm{A} 2}$ ) is an inherited risk factor for bypass occlusion, myocardial infarction, and death. Thromb Haemost 2000;81:404-407.

26 Bray PF: Platelet glycoprotein polymorphisms as risk factors for thrombosis. Curr Opin Hematol 2000;7:284-289.

27 Zotz RB, Winkelmann BR, Müller C, Boehm BO, März W, Scharf RE: Association of polymorphisms of platelet membrane integrins $\alpha_{2} \beta_{3}\left(\mathrm{HPA}-1 \mathrm{~b} / \mathrm{Pl}^{\mathrm{A} 2}\right.$ ) and $\alpha$ II $(\alpha 2807 \mathrm{TT})$ with premature myocardial infarction. J Thromb Haemost 2005;3: 1522-1529.

28 Scharf RE, Deitenbeck R, Giers G, Zotz RB: Increased binding of soluble fibrinogen to the platelet glycoprotein IIb-IIIa receptor related to the polymorphism of the GPIIIa gene (HPA-1b/PlA2). Blood 1997;90:256a.

29 Goodall AH, Curzen N, Panesar M, Hurd C, Knight CJ, Ouwehand WH, Fox KM: Increased binding of fibrinogen to glycoprotein IIIa-proline 33 (HPA-1b, $\mathrm{Pl}^{\mathrm{A} 2}, \mathrm{Zw}^{\mathrm{b}}$ ) positive platelets in patients with cardiovascular disease. Eur Heart J 1999;20: 742-747.

30 Bennett JS, Catella-Lawson F, Rut AR, Vilaire G, Qi W, Kapoor SC, Murphy S, FitzGerald GA: Effect of the PlA2 alloantigen on the function of $\beta 3$ integrins in platelets. Blood 2001;97:3093-3099.

31 Feng D, Lindpaintner K, Larson MG, Rao VS, O'Donnell CJ, Lipinska I, Schmitz C, Sutherland PA, Silberschatz H, D'Agostino, M, Muller JE, Myers RH, Levy D, Tofler GH: Increased platelet aggregability associated with platelet GPIIIa $\mathrm{Pl}^{\mathrm{A} 2}$ polymorphism: the Framinham Offspring Study. Arterioscler Thromb Vasc Biol 1999;19:1142-1147.

32 Feng D, Lindpaintner K, Larson MG, O'Donnell CJ, Lipinska I, Sutherland PA, Mittleman M, Muller JE, D'Agostino RB, Levy D, Tofler GH: Platelet glycoprotein IIIa $\mathrm{Pl}(\mathrm{A})$ polymorphism, fibrinogen, and platelet aggregability: The Framingham Heart Study. Circulation 2001;104:140-144.

33 Michelson AD, Furman MI, Goldschmidt-Clermont P, Mascelli MA, Hendrix C, Coleman L, Hamlington J, Barnard MR, Kickler T, Christie DJ, Kundu S, Bray PF: Platelet GPIIIa $\mathrm{Pl}^{\mathrm{A}}$ polymorphisms display different sensitivities to agonists. Circulation 2000;101:1013-1018.
34 Scharf RE, Dorenbusch K, Kirchhoff EM: Effects of the $1565 \mathrm{~T} / \mathrm{C}$ polymorphism (HPA-1) of the $\beta 3$ gene of integrin $\alpha_{\mathrm{II}} \beta_{3}$ on its surface expression and platelet secretion (submitted).

35 Weber AA, Jacobs, Meila D, Weber S, Zotz RB, Scharf RE, Kelm M, Strauer BE, Schrör K: No evidence for an influence of the human platelet antigen-1 polymorphism on the antiplatelet effects of glycoprotein IIb-IIIa inhibitors. Pharmacogenetics 2002;12:581-583.

36 Savage B, Saldivar E, Ruggeri ZM: Initiation of platelet adhesion by arrest onto fibrinogen or translocation on von Willebrand factor. Cell 1996; 84:289-297

37 Savage B, Almus-Jacobs F, Ruggeri ZM: Specific synergy of multiple substrate-receptor interactions in platelet thrombus formation under flow. Cell 1998;94:657-666.

38 Ruggeri ZM: Von Willebrand factor, platelets and endothelial cell interactions. J Thromb Haemost 2003;1:1335-1342.

39 Stoldt VR, Peveling J, Loncar R, Beck A, Aurich V, Scharf RE: Evaluation of platelet thrombus formation under flow. Blood 2005;106:3954.

40 Vijayan KV, Goldschmidt-Clermont PJ, Roos C Bray PF: The $\mathrm{Pl}^{\mathrm{A} 2}$ polymorphism of integrin $\beta 3$ enhances outside-in signaling and adhesive functions. J Clin Invest 2000;105:793-802.

41 Vijayan KV, Huang TC, Liu Y, Bernardo A, Dong JF, Goldschmidt-Clermont PJ, Alevriadou BR, Bray PF: Shear stress augments the enhanced adhesive phenotype of cells expressing the Pro33 isoform of integrin $\beta 3$. FEBS Lett 2003;540:41-46.

42 Vijayan KV, Liu Y, Sun W, Ito M, Bray PF: The Pro33 isoform of integrin beta3 enhances outside-in signaling in human platelets by regulating the activation of serine/threonine phosphatases. J Biol Chem 2005;280:21756-21762.

43 Bray PF: Integrin polymorphisms as risk factors for thrombosis. Thromb Haemost 1999;82:337-344.

44 Williams MS, Bray PF: Genetics of arterial prothrombotic risk states. Exp Biol Med 2001;226: 409-419.

45 Lane DA, Grant PJ: Role of hemostatic gene polymorphisms in venous and arterial thrombotic disease. Blood 2000;95:1517-1532.

46 Mikkelsson J, Perola M, Laippala P, Savolainen V, Pajarinen J, Lalu K, Penttilä A, Karhunen PJ: Glycoprotein IIIa polymorphism associates with progression of coronary artery disease and with myocardial infarction in an autopsy series of middleaged men who died suddenly. Arterioscler Thromb Vasc Biol 1999;19:2573-2578. 